\title{
Development of postural balance in Brazilian children aged 4-10 years compared to young adults
}

\section{Desenvolvimento do equilíbrio postural em crianças brasileiras de 4 a 10 anos de idade comparadas com adultos-jovens}

\author{
Luiz Fernando Cuozzo Lemos \\ Ana Cristina de David² \\ Carlos Bolli Mota ${ }^{3}$
}

Abstract - The aim of the present study was to analyze the development of postural balance in 4- to 10-year-old Brazilian children, compared to a group of young adults under normal and deprived visual conditions. Body sway was assessed through average velocity and sway range at the center of pressure $(\mathrm{CoP})$ in the anteroposterior and medio-lateral directions, obtained on a force platform (AMTI, Inc.). Sample was composed of 153 children (of seven different age groups) and 47 adults. Inter-group comparisons were performed using one-way ANOVA and Tukey's post-hoc test at 5\% significance level. The results showed that starting at 9 and 10 years of age, $\mathrm{CoP}$ velocity and displacement values for children were similar to values for adults under restricted visual conditions; however, there were differences between children and adults. The findings suggest that visual stimulation plays a prominent role in the balance of individuals up to 10 years of age, with significant evidence that postural balance is not fully developed up to that age.

Key words: Child; Development; Growth; Maturation; Postural balance.

Resumo - O objetivo do presente trabalho foi analisar o desenvolvimento do equilibrio postural de crianças brasileiras de 4 a 10 anos de idade, comparar com um grupo de adultos-jovens, como uso da visão normal e na ausência da visão. A oscilação corporal foi avaliada por meio da velocidade media e amplitude de oscilação do centro de pressão (CoP) nas direçôes ântero-posterior e médio-lateral, obtidas por meio de uma plataforma de força (AMTI, Inc.). O grupo de estudo foi composto por 153 crianças (de sete diferentes grupos etários) e 47 adultos-jovens. As comparaçôes inter-grupos foram feitas com o uso dos testes ANOVA one-way e o post-hoc de Tukey com um nivel de significância de 5\%. Os resultados mostraram que por volta de 9 e 10 anos de idade os valores da velocidade e da amplitude de deslocamento do CoP passam a ser similares entre crianças e adultos-jovens; no entanto, com a restrição do uso da visão, houve diferenças entre crianças e adultos-jovens. Os achados sugerem que o estimulo visual tem um papel importante no equilíbrio postural de individuos até os seus 10 anos de idade, com significativas evidencias que o controle postural não está totalmente desenvolvido até essa faixa etária.

Palavras-chave: Crescimento; Crianças; Desenvolvimento; Equilíbrio postural; Maturação.
1 Faculty Cenecista of Osório. Department of Physical Education. Osório, RS. Brazil.

2 University of Brasília. School of Physical Education. Laboratory of Biomechanics. Brasília, DF. Brazil.

3 Federal University of Santa Maria. School of Physical Education and Sports. Laboratory of Biomechanics. Santa Maria, RS. Brazil.

Received: 11 March 2016 Accepted: 20 July 2016 


\section{INTRODUCTION}

In order to maintain postural balance, human beings rely on three main sources of information, namely: visual, proprioceptive and vestibular ${ }^{1,2}$. Information is sent by afferent pathways to the central nervous system, where it is processed and generates the appropriate motor response to correct any possible disruption or imbalance ${ }^{3,4}$.

In children, the maturation process does not take place evenly in all body systems; some develop first than others. There is evidence that the development of the three sensory systems occurs sequentially, with maturation of proprioceptive system occurring before the visual system. The last to develop is the vestibular system ${ }^{2,3,7}$. An aspect that has not been fully elucidated in literature is the age at which children achieve adult-like balance. Studies have found that decreased body sway of children may occur at different ages. Some studies have reported maturation of the proprioceptive system at around 3-4 years of age as a visual influence on standing stability is established at adult levels only by the age of 9 to 15 years ${ }^{5-8}$. Most of these studies used stabilometry as an assessment method to quantify postural balance ${ }^{2,7,9,10}$. However, there is still limited data on the organization of visual, proprioceptive and vestibular systems regarding posture control in children.

In this context, the present study aimed to compare the development of postural balance in Brazilian children aged 4-10 years with a group of young adults under regular and deprived visual conditions. Investigations of posture mechanisms during childhood are necessary to identify postural control development disturbances. This study will try to clarify this issue using appropriate techniques to evaluate center of pressure displacement in a large number of subjects divided into groups. The hypothesis is that significant changes occur in the postural control with advancing chronological age, mainly due to the use of the visual system.

\section{METHODOLOGICAL PROCEDURES}

\section{Study group}

The study group included 153 4- to 10-year-old children and 47 adults, divided into groups totaling 200 individuals, as shown in Table 1.

Children were students at a private school located in Brasília, Brazil. All participants received permission to participate in the study from their parents or guardians, who signed an Informed Consent Form, according to the terms of National Health Council Resolution 466/2012. The research study had been previously approved by the Ethics Committee on Human Research of the University of Brasília.

The inclusion criteria - for adults and children - were absence of musculoskeletal disorders, diabetes, hypertension, complaints of dizziness or vertigo and any kind of mental deficit that could alter postural balance. These data were checked in interviews with participants, teachers and/or 
parents or guardians. Exclusion criteria included lack of signature on the Informed Consent Form, overweight or obesity, intake of any drug that might influence postural balance, identification of any musculoskeletal injury, or reports by teachers or parents of any delay in the child's development of coordination.

Overweight and obesity in adults were measured through body mass index (BMI). The criterion adopted for children was BMI proposed by Cole et al. ${ }^{11}$.

For children allowed to participate in the study, days and times were scheduled for data collection, which was performed at school during school hours. These students practiced physical activities, motricity classes and regular physical education classes in their school environment.

Adults who took part in the research were Physical Education students at the University of Brasília. Physical activities performed by the group of adults combined with their commutes and other sports they practiced met the traditional recommendation of at least 150 minutes weekly (30 minutes, five days a week) of light-to-moderate physical activity ${ }^{12}$.

\section{Techniques}

An AccuSway Plus portable force platform from AMTI (Advanced Mechanical Technology, Inc., Watertown, MA, USA) was used to quantify center of pressure displacement. Data were collected from children at school and from adults at the UnB Laboratory of Biomechanics. Environmental conditions were similar, taking place in a quiet room without outside interference (noise). The force platform was placed horizontally. Data were visualized through the frequency spectrum, showing a high-quality signal with little noise interference.

Each individual was tested three times for each condition - three trials with eyes open and three trials with eyes covered with a blindfold, both in the bipedal stance. All tests occurred randomly among the tested conditions. All samples were obtained at $100 \mathrm{~Hz}$ frequency and 30 seconds of time acquisition. The interval between collections was one minute. Individuals were asked to fix their gaze on a point two meters away, marked on a wall at eye level. Arms should remain along the body, motionless, as should the rest of the body.

The distance between the right and left trochanters of each individual was measured using a caliper. That value was regarded as the support base (hip width), on which individuals should remain throughout data collection. The position was marked on the force platform with masking tape to avoid its displacement during all collection attempts.

To eliminate possible interfering noises in the signal, a low-pass fourthorder Butterworth filter with $10 \mathrm{~Hz}$ cutoff frequency was developed in the Matlab (MathWorks Inc., Cambridge, MA, USA) environment.

After calculating the center of pressure at each time, the following variables were calculated: medio-lateral sway range ( $\mathrm{aCOPml})$, anteroposterior sway range (aCOPap) and mean displacement velocity of the center 
of pressure $(\mathrm{Vm})$. These variables are widely used in literature $\mathrm{r}^{1,2,7,9,13}$ and were used in this study for comparison with other studies.

Data were first submitted to descriptive statistics. Normality was checked by the Shapiro-Wilk test, and the equality of variances was assessed using Levene's test. Group averages were compared by one-way ANOVA. Possible differences were verified by Tukey's post-hoc test. A 5\% significance level was adopted.

\section{RESULTS}

As expected, older students showed higher mass and height (Table 1). Postural balance control also increased according to chronological age, under both open- and closed-eyes conditions (Figures 1, 2 and 3).

Table 1. Study group features. Mean (X) and standard deviation (S) values for age (years), individuals (number of individuals), mass (kilograms) and height (meters) of children and adults included in the study.

\begin{tabular}{lcccccccc}
\hline GROUPS & \multicolumn{2}{c}{ Age (years) } & \multicolumn{2}{c}{ Individuals $(\mathrm{n})$} & \multicolumn{2}{c}{ Mass $(\mathrm{kg})$} & \multicolumn{2}{c}{ Height $(\mathrm{m})$} \\
\hline & $\mathrm{X}$ & $\mathrm{S}$ & Male & Female & $\mathrm{X}$ & $\mathrm{S}$ & $\mathrm{X}$ & $\mathrm{S}$ \\
\hline 4 years $(\mathrm{n}=20)$ & 4.37 & 0.27 & 14 & 6 & 18.68 & 3.39 & 1.09 & 0.06 \\
5 years $(\mathrm{n}=29)$ & 5.43 & 0.31 & 19 & 10 & 20.86 & 3.37 & 1.13 & 0.05 \\
6 years $(\mathrm{n}=26)$ & 6.32 & 0.29 & 13 & 13 & 22.85 & 3.07 & 1.18 & 0.05 \\
7 years $(\mathrm{n}=22)$ & 7.47 & 0.24 & 11 & 11 & 24.31 & 4.34 & 1.24 & 0.05 \\
8 years $(\mathrm{n}=22)$ & 8.42 & 0.29 & 12 & 10 & 29.63 & 6.85 & 1.31 & 0.05 \\
9 years $(\mathrm{n}=20)$ & 9.38 & 0.29 & 10 & 10 & 34.43 & 8.78 & 1.38 & 0.06 \\
10 years $(\mathrm{n}=14)$ & 10.38 & 0.25 & 6 & 8 & 35.99 & 6.28 & 1.44 & 0.06 \\
Adults $(\mathrm{n}=47)$ & 22.36 & 3.64 & 24 & 23 & 64.46 & 13.08 & 1.70 & 0.08 \\
\hline
\end{tabular}

Figure 1 shows postural balance results for variable aCOPap in each age group, for both sexes, under open-eyes (EO) or closed-eyes (EC) conditions.

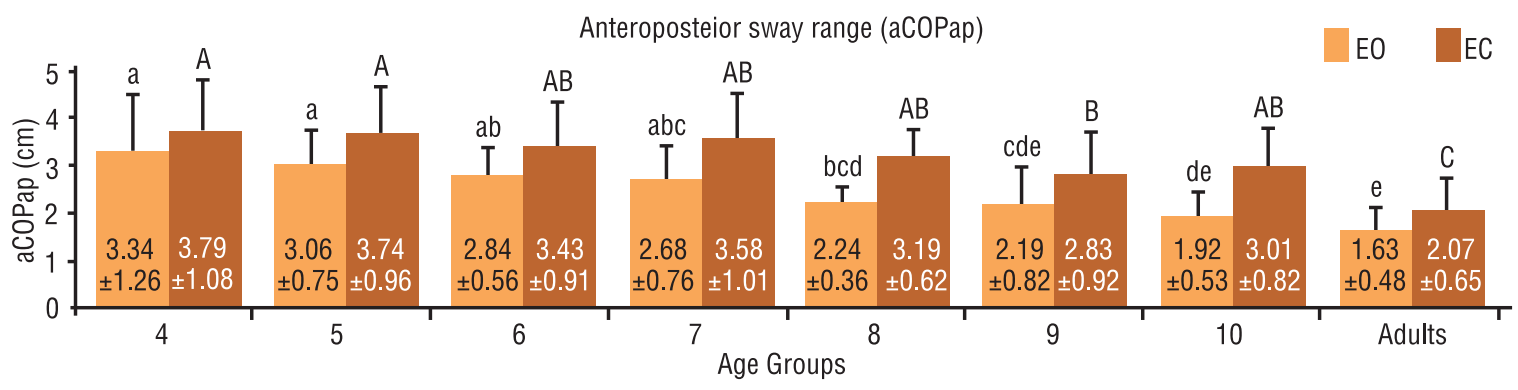

Figure 1. Mean and standard deviation values for the aCOPap variable in 4- to 10-year-old children and adults, in open-eyes (EO) or closed-eyes (EC) condition. One-Way ANOVA showed significant differences between groups $(p<0.001)$. The different abcde superscript letters (open-eyes condition) and $A B C$ superscript letters (closed-eyes condition) are significantly different between groups, and identical

In younger children (4 to 7 years), it is possible to observe that $\mathrm{EO}$ and EC showed no statistically significant difference in postural balance control for the anteroposterior direction (Figure 1).

Figure 2 shows postural balance results for variable aCOPml in each age group, for both genders, under open-eyes (EO) or closed-eyes (EC) conditions. 


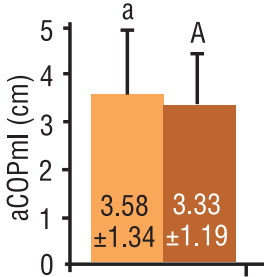

4

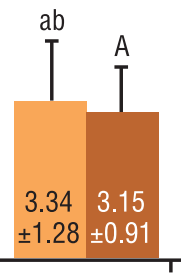

5

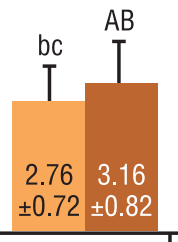

6

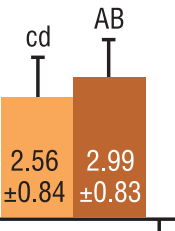

7 Age Groups

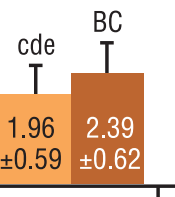

8

Figure 2. Mean (X) and standard deviation (S) values for variable aCOPml in 4- to 10-year-old children and adults in open-eyes (E0) or closed-eyes (EC) condition. One-Way ANOVA showed significant differences between groups $(p<0.001)$. The different abcde superscript letters (open-eyes condition) and $A B C$ superscript letters (closed-eyes condition) are significantly different between groups, and identical letters showed no difference according to the Tukey's test $(p<0.05)$.

Unlike the anteroposterior direction, EO in the medio-lateral direction showed visible differences in postural balance for every two-year age difference. However, when visual information is removed (EC), there is no longer any statistical difference among younger children (Figure 2).

Figure 3 presents postural balance results for variable $\mathrm{Vm}$ in each age group, for both genders, under open-eyes (EO) or closed-eyes (EC) conditions.

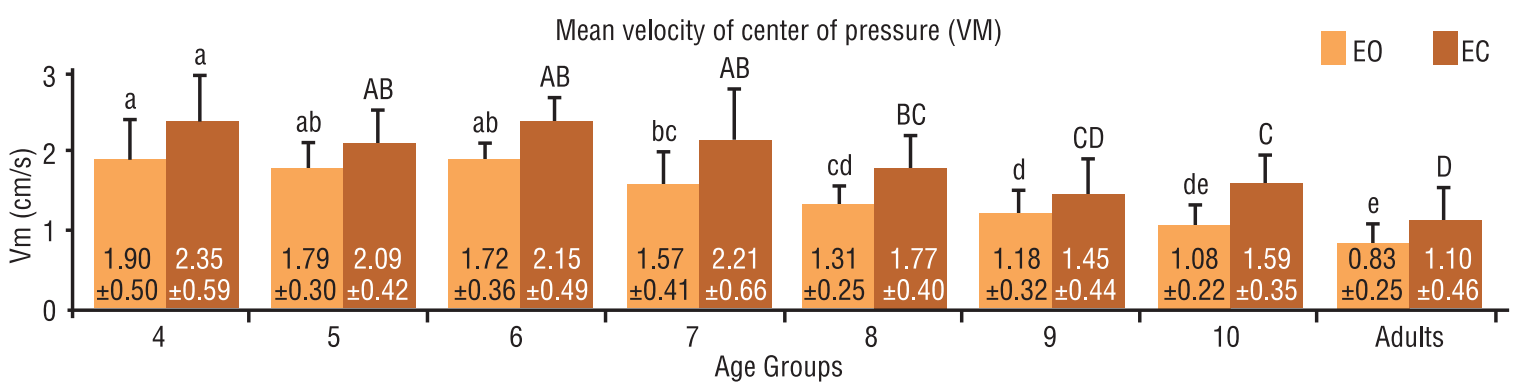

Figure 3. Mean $(X)$ and standard deviation (S) values for variable $\mathrm{Vm}$ in 4- to 10-year-old children and adults in open-eyes (E0) or closed-eyes (EC) condition. One-Way ANOVA showed significant differences between groups $(p<0.001)$. The different abcde superscript letters (open-eyes condition) and ABC superscript letters (closed-eyes condition) are significantly different between groups, and identical letters showed no difference according to the Tukey's test $(p<0.05)$.

Variable $\mathrm{Vm}$ also improves with postural control with increasing age. However, once again, there is increased difficulty in controlling balance in the closed-eyes condition (EC), with more similar results among younger groups (Figure 3).

Analyzing the results for children in all three postural balance variables used in the present study (aCOPap, aCOPml and Vm), it could be concluded that children around 9 or 10 years of age show no statistically significant differences in the $\mathrm{EO}$ condition when compared to adults (Figures 1,2 and 3).

For the EC condition, however, only variable $\mathrm{Vm}$ for children aged 9 years showed no statistically significant difference compared to adults. The other variables (aCOPap and aCOPml) for all age groups showed statistically significant differences compared to adults (Figures 1,2 and 3).

\section{DISCUSSION}

With regard to the development of postural balance behavior with increasing chronological age, the results reported in the present study were corroborated by another study ${ }^{3}$. The authors performed a study with 
195 children divided in four age groups (6-8, 8-10, 10-12 and 12-14), and as in the present study, children were compared to young adults. Under conditions similar to those used in the present study, it was observed that, in general, there are differences between children aged 6, 7 and 8 year and older children or young adults ${ }^{3}$. The differences expressed in that study, like those shown in the present study, are maximized in the absence of visual information. The authors attributed that phenomenon to immature postural balance control, resulting in loss of stability in situations of sensorial conflict, which is only fully developed around 12 years of age ${ }^{3}$.

The findings of the present work regarding the age of children to achieve adult-like sway standards are dissimilar to those obtained by Hsu et al. ${ }^{2}$, who analyzed the postural balance control of 3- to 12-year-old children and adolescents on a force platform using variables mean sway velocity and $\mathrm{CoP}$ sway area. Hsu et al. ${ }^{2}$ found that postural balance in 7-year-old children showed no statistically significant difference compared to values obtained for adults for mean velocity of $\mathrm{CoP}$, either in the open-eyes or closed-eyes conditions. For sway area, however, children ceased differing from adults at an even younger age: 6 .

The results of Hsu et al. ${ }^{2}$ are corroborated by Assaiante ${ }^{14}$, who reported that upright postural balance occurs up to 6 years of age, when the child reaches effective and integrated coordination of upper and lower limbs. During this period, there is also an increase in the muscular activity of the gastrocnemial muscle, which helps correct body sway ${ }^{14}$. Assaiante ${ }^{14}$ also reported that around the age of 7 years, children achieve the standards of balance control used by adults, and that the predominant use of the afferent visual pathway is not restricted to infants but continues up to the age of six years.

In this context, a study was conducted with 148 children to investigate postural control mechanisms, their variations and development in the absence of visual information in three groups of children (7, 9 and 11 years $)^{7}$. Groups were assessed using a force platform under two conditions: open eyes and closed eyes with 60 seconds of acquisition for each experiment. The results of the present study confirmed the hypothesis of a discontinuous development of postural control during growth, with a clear transition around 9 to 11 years of age, when children begin to show efficient control standards, even in the closed-eyes condition. These results were not observed in the groups of children aged 7 and 9 years under CoP displacement analysis. Nevertheless, it was observed that at the age of 9 years, there is a more mature afferent proprioceptive selection to help maintain postural balance, resulting in more high-frequency contributions for postural stability maintenance ${ }^{7}$. Data from that study suggest that children under 9 years of age need greater input of visual information to control posture compared to older children, which is manifested as greater $\mathrm{CoP}$ sway under closed-eyes conditions ${ }^{7}$. Evidence has shown that the critical point in the development of visual control balance is around 10 years of age.

However, even if considering that the children assessed in the present study reached adult values at an older age compared to the study by Hsu 
et al. ${ }^{2}$, if we compare the scores obtained for variable mean CoP velocity in both studies for the open-eyes condition, some interesting points can be observed. In the study by Hsu et al. ${ }^{2}$, children aged 4, 5 and 6 years reached $2.13 \pm 0.09,1.83 \pm 0.08$ and $1.82 \pm 0.09 \mathrm{~cm} / \mathrm{s}$ of mean CoP velocity, respectively. These values are somewhat higher than the results of this study, which means that there was greater body sway velocity, but the difference in values between for studies with children aged 5 and 6 years are, respectively, 0.04 and $0.1 \mathrm{~cm} / \mathrm{s}$, which can be regarded as similar. Values for adults in the study by Hsu et al. ${ }^{2}$ for variable $\mathrm{Vm}$ in the openeyes condition were $1.27 \pm 0.08 \mathrm{~cm} / \mathrm{s}$, while values for adults in this study were $0.83 \pm 0.25 \mathrm{~cm} / \mathrm{s}$. These differences may be related to the different ages of adults in both works; in the present study, they aged $22.36 \pm 3.64$ years, while in Hsu et al. ${ }^{2}$ the average age was $32 \pm 10$ years - a difference of almost 10 years. The lower body sway values obtained from adults in this study compared to Hsu et al. ${ }^{2}$ are probably due to changes in lifestyle that may occur in a 10-year life span. Generally, younger adults have a more active life compared to older adults, and it is known that physical activity is a very positive factor in individual body balance ${ }^{15}$. Therefore, it was evident that differences in body balance persisted beyond the age of 6 years compared to adults who participated in this study. With regard to older adults, no differences were found in literature ${ }^{2}$.

A study by Ionescu et al. ${ }^{16}$ reported that 12 -year-old adolescents do not show the same level of stance balance control as young adults (20.1 \pm 0.2 years old). The study was conducted with an instrument known as computerized dynamic posturography (Balance Quest), which measures body balance using $\mathrm{CoP}$ displacement variables under six different conditions that can manipulate afferent sensorial information. The equipment also calculates the usage rate of every afferent pathway in maintaining balance (visual, vestibular and proprioceptive). The authors reported that 12-year-old adolescents scored lower than young adults in stability, showing higher dependency on visual aids, and concluded with the statement that the maturation process occurs throughout childhood until the age of 12 years. Of the three sensorial pathways used by children, the vestibular system seems to be the least effective for postural control purposes ${ }^{16}$.

These findings are consistent with the results of Cherng et al. ${ }^{17}$, who compared young adults aged 19-23 years with children aged 7-10 years using a balance assessment tool called Equitest. According to the authors, the functional efficiency of the vestibular system is still developing in 10-year-old children ${ }^{17}$.

In the study by Tsai et al., ${ }^{18}$ children with delayed coordination development showed statistically significant body sways, greater than in children considered normal, for almost all conditions mentioned by the authors. One of the conclusions presented by the above authors was the importance of choosing the subjects for stabilometric studies in order to prevent the inclusion of children with such deficits ${ }^{18}$, a condition observed in the present study. 
In a study comparing balance kinetic data on 8- to 11-year-old children and adolescents, practicing physical activity or not, the authors found no difference according to physical activity practice, but the values compared to the children of the present research, under the same test conditions, were different ${ }^{19}$. For the values of variable aCOPap, both physical activity practitioners and non-practitioners had greater values compared to adults and children in this study for the open-eyes condition. However, in the closed-eyes condition, sway values were the lowest in all groups of children who participated in the present study, and higher than values obtained for adults. The results obtained by Oliveira et al. ${ }^{19}$ for variable aCOPml in both physical activity practitioners and non-practitioners in the open-eyes condition showed higher results only compared to children aged 10 year and adults in the present study. In the closed-eyes condition, sways values were lower compared to all groups of children, and higher only when compared to adults in this study ${ }^{19}$.

Thus, it could be concluded that visual dependency by older children in the present study is higher than in the study by Oliveira et al. ${ }^{19}$; and as previously mentioned, sways values were lower in the open-eyes condition and higher in the closed-eyes condition. These findings also show that when the children of the present study were able to use the three different afferent pathways to maintain balance (visual, vestibular and proprioceptive), they were quite successful in performing the required task, indicating an integration of the stimuli received and the choice for the best option when it came to guaranteeing stance balance. According to Horak and Macpherson ${ }^{20}$, integration of information brought by the three sensorial pathways is a fundamental step in the postural balance maintenance, as the system will connect and link available sensorial information and define the share that each part will dedicate to posture balance maintenance. The contribution given by a channel is selected according to its importance in the global solution employed for the maintenance of posture balance. The most useful sensorial channels predominate over the least useful ones ${ }^{3,8,21}$.

In addition to the choice of the most reliable afferent pathway to maintain posture balance, the strategy used to coordinate and control the upright stance balance is also quite important. Some authors highlight that the age group of 7-8 years is marked by a change in the strategy used for balance maintenance and coordination ${ }^{22,23}$. According to the authors, children in this age group start using the head-trunk stabilization strategy, like adults do, which may produce worse results than results shown by younger children when maintaining upright stance balance on the force, because the child is going through the learning process of acquiring new strategies $^{22}$.

In a study by Rival et al. ${ }^{22}$, the authors analyzed postural balance in 6-, 8- and 10-year-old children and in a group of adults (24-years-old), in the closed-eyes condition on a force platform, comparing variables $\mathrm{Vm}$ and $\mathrm{CoP}$ amplitude in both groups. In agreement with data in the present study, the mean $\mathrm{CoP}$ velocity showed a linear decrease inverse to age, but 
CoP amplitude reached its top value at the age of 8 years, followed by 6 and 10-year-old children and adults. With the results above, Rival et al. ${ }^{22}$, statistically concluded that up to the age of 10 in the closed-eyes condition, children are not able to produce the same results obtained in the group of adults. These findings confirm the results of the present study, as they were similar to those obtained by River et al. ${ }^{22}$, using the same variables and conditions (closed eyes).

The limitations of this investigation are related to the limited number of subjects in each group and/or absence of other groups of children in public schools. Another limitation that should be taken into consideration is that the data presented in this paper only address static postural control. Thus, the findings are limited to relate to dynamic postural control data.

\section{CONCLUSION}

It was concluded that postural balance in Brazilian children aged 9-10 years showed no difference when compared to young adults in the openeyes condition. However, in closed-eyes condition, all children differed in postural balance from the group of adults, except for children aged 9 years, which showed some differences in the mean velocity of variable center of pressure. These results reveal that children up to 10 years of age are more dependent on visual aids to maintain postural balance than adults.

For younger Brazilian children (4 to \pm 7 years old), the results show a slow improvement of postural control as result of chronological age advances, but also larger oscillations when compared to the rest of the groups.

The data reported in the present study may be used as reference for a comparison of balance control values for children and groups with different features, such as obese or visually impaired people.

\section{Acknowledgements}

The authors would like to thank CAPES.

\section{REFERENCES}

1. D'Hondt E, Deforche B, Bourdeaudhuij I, Gentier I, Tanghe A, Shultz S, Lenoir M. Postural balance under normal and altered sensory conditions in normal-weight and overweight children. Clin Biomech 2011;26(1):84-9.

2. Hsu YS, Kuan CC, Young YH. Assessing the development of balance function in children using stabilometry. Int J of Pediatr Otorhinolaryngol 2009;73(5):737-40.

3. Ferber-Viart C, Ionescu E, Morlet T, Froehlich P, Dubreuil C. Balance in healthy individuals assessed with Equitest: Maturation and normative data for children and young adults. Int J of Pediatr Otorhinolaryngol 2007;71(7):1041-6.

4. Danis CG, Krebs DE, Gill-Body KM, Sahrmann S. Relationship between standing posture and stability. Physical Therapy 1998;78(5):502-17.

5. Cumberworth VL, Patel NN, Rogers W, Kenyon GS. The maturation of balance in children. J Laryngol Otol 2006;121(5):449-54.

6. Steindl R, Kunz K, Schrott-Fischer A, Scholtz AW. Effect of age and sex on maturation of sensory systems and balance control. Dev Med Child Neurol 2006;48(6):477-82. 
7. Schmid M, Conforto S, Lopez L, Renzi P, Dalessio T. The development of postural strategies in children: a factorial design study. J Neuroeng Rehabil 2005;30:2-29.

8. Oie KS, Kiemel T, Jeka JJ. Multisensory fusion: simultaneous re-weighting of vision and touch for the control of human posture. Cognitive Brain Res 2002;14(1):164-76.

9. Blanchard Y, McVeigh R, Graham M, Cadet M, Mwilambwe K, Scott C. The influence of ambient lighting levels on postural sway in healthy children. Gait Posture 2007;26(3):442-5.

10. Bhattacharya A, Shukla R, Dietrich KN, Bornschein RL. Effect of early lead exposure on the maturation of children's postural balance: A longitudinal study. Neurotoxicol Teratol 2006;28(3):376-85.

11. Cole TJ, Bellizzi MC, Flegal KM, Dietz WH. Establishing a standard definition for child overweight and obesity worldwide: international survey. BMJ 2000;320(7244):1240-3.

12. American College of Sports Medicine, ACSM. Stand position on the appropriate intervention strategies for weight loss and prevention of weight regain for adults. Med Sci Sport Exer 2001;33(12)2145-56.

13. Baccouch R, Zarrouk N, Chtourou H, Rebai H, Sahli S. Time-of-day effects on postural control and attentional capacities in children. Physiol Behav 2015;142(1):146-51.

14. Assaiante C. Development of locomotor balance control in health children. Neurosci Biobehav R 1998;22(4):527-32.

15. Annear MJ, Cushman G, Gidlow B. Leisure time physical activity differences among older adults from diverse socioeconomic neighborhoods. Health Place 2009;15(2):482-90.

16. Ionescu E, Morlet T, Froehlich P, Ferber-Viart C. Vestibular assessment with Balance Quest: Normative data for children and young adults. Int J of Pediatr Otorhinolaryngol 2006;70(8):1457-65.

17. Cherng RJ, Hsu YW, Chen YJ, Chen JY. Standing balance of children with developmental coordination disorder under altered sensory conditions. Hum Movement Sci 2007;26(6):913-26.

18. Tsai CL, Wu SK, Huang CH. Static balance in children with developmental coordination disorder. Hum Movement Sci 2008;27(1):142-53.

19. Oliveira TP, Santos AMC, Andrade MC, Ávila AOV. Avaliação do controle postural de crianças praticantes e não praticantes de atividade física regular. Braz J Biomech 2008;9(16):41-6.

20. Horak FB, Macpherson JM. Postural orientation and equilibrium In: Rowell LB \& Shepard JT. (Eds), Handbook of physiology (pp. 255-292). New York: Oxford University press 1996.

21. Meredith MA. On the neuronal basis for multisensory convergence: a brief overview. Cognitive Brain Res 2002;14(1):31-40.

22. Rival C, Ceyte H, Olivier I. Developmental changes of static standing balance in children. Neurosci Lett 2005;376(2):133-6.

23. Kirshenbaum N, Riach CL, Starkes JL. Non-linear development of postural control and strategy use in young children: a longitudinal study. Exp Brain Res 2001;140(4):420-31.

\section{CORRESPONDING AUTHOR}

Luiz Fernando Cuozzo Lemos School of Physical Education and Sports, Laboratory of Biomechanics Federal University of Santa Maria, Labiomec, Santa Maria, RS, Brazil. Faixa de Camobi, km 9 , CEP: 97105-900, Santa Maria-RS, Brazil

E-mail: luizcanoagem@yahoo. com.br 